\title{
¿EL PRINCIPIO DEL FIN DE LA IDENTIFICACIÓN POR SEXO?*
}

\author{
Elena Trujillo Villamor \\ Centro de Estudios de Consumo \\ Universidad de Castilla-La Mancha
}

Resumen: Tras el revuelo mediático por la filtración del borrador de la Ley trans que prepara el Gobierno, en este documento se analizan los problemas que podrían surgir si el borrador se convirtiese finalmente en ley y las disposiciones más controvertidas como el límite de edad para solicitar el cambio de sexo por sí mismo o la eliminación de cumplir con requisitos médicos para acceder al cambio en la mención registral del sexo. ¿Será el final de la identificación por sexo?

Palabras clave: Mención registral del sexo, interés superior del menor, mayoría de edad, autodeterminación de género, nombre

Title: The beggining of the end of gender identification?

Abstract: In this document we analyze the problems that could be caused by the approbation of the trans law that is being prepared by the government, which draft leaking has caused a huge media hype, as the most controversial provisions, such as the age limit to self-request gender change or the suppression of the medical

\footnotetext{
* Trabajo realizado en el marco del Contrato con referencia 2020-COB-9847 financiado con cargo al Proyecto Convenio de colaboración entre la UCLM y el Ilustre Colegio Notarial De Castilla-La Mancha (17 enero 2014) (OBSV) con referencia CONV140025, que dirige el Prof. Ángel Carrasco Perera; en el marco del Proyecto de Investigación PGC2018-098683-B-I00, del Ministerio de Ciencia, Innovación y Universidades (MCIU) y la Agencia Estatal de Investigación (AEI) cofinanciado por el Fondo Europeo de Desarrollo Regional (FEDER) titulado "Protección de consumidores y riesgo de exclusión social", dirigido por Ángel Carrasco Perera y Encarna Cordero Lobato; a la Ayuda para la financiación de actividades de investigación dirigidas a grupos de la UCLM Ref.: 2020-GRIN-29156, denominado "Grupo de Investigación del Profesor Ángel Carrasco" (GIPAC) y a la ayuda para la realización de proyectos de investigación científica y transferencia de tecnología, de la Junta de Comunidades de Castilla-La Mancha cofinanciadas por el Fondo Europeo de Desarrollo Regional (FEDER) para el Proyecto titulado "Protección de consumidores y riesgo de exclusión social en Castilla-La Mancha" (PCRECLM) con Ref.: SBPLY/19/180501/000333 dirigido por Ángel Carrasco Perera y Ana Isabel Mendoza Losana.
} 
requirements' fulfillment to change gender's registration mention. Will it be the end of gender identification?

Keywords: Gender's registration mention, underage's best interests/children's best insterests, legal age, gender self-determination, name

SUMARIO: 1. Marco jurídico. 2. Derecho a la identidad de género (art.5). 3. Rectificación registral de la mención relativa al sexo de las personas (arts. 9 a 18). 3.1 Legitimación (art. 9). 3.1.1 Los menores independientemente de la edad podrán cambiar su mención registral del sexo. 3.1.2 Los menores de más de 16 años no necesitan representantes legales para cambiar su mención registral relativa al sexo. 3.1.3 No hay que acreditar tratamiento hormonal ni diagnóstico de disforia de género (art. 12). 3.2 Los menores podrán cambiar su nombre de acuerdo exclusivamente a su identidad de género (art. 17). 3.3 La mención registral relativa al sexo puede desaparecer. 3.4 Los extranjeros también pueden adaptar su documentación (art. 18). 4. ¿Cómo se regula esta cuestión en los países de nuestro entorno? 5. Medidas en el ámbito sanitario. 6. Conclusiones. 7. Bibliografía.

El dos de febrero de 2021 saltó al dominio público el borrador de la Ley trans que se estaba preparando en el seno del Gobierno, acaparando numerosos titulares y espacio televiso y radiofónico. Este borrador ha generado un debate que pivota sobre la existencia de un derecho a la autodeterminación del género y si concurren requisitos o limitaciones para ejercerlo.

Este borrador persigue regular de forma integral para todo el territorio nacional la situación de las personas trans en el ámbito educativo, laboral, deportivo, sanitario y el más relevante, el referente al cambio de la mención registral del sexo, en el cual se centrará este artículo. Sin embargo, no se puede soslayar que este documento se trata de un borrador y no de un anteproyecto de ley y de momento no parece tener fecha para iniciar los trámites preceptivos para su aprobación.

\section{Marco jurídico}

Para alcanzar una mayor comprensión de las disposiciones de este borrador, hay que poner de relieve varios aspectos relativos a la regulación del colectivo trans. A nivel internacional, la Organización Mundial de la Salud (en adelante, OMS) aprobó en la Asamblea Mundial de la Salud en su reunión anual en mayo de 2019 la revisión de 2018 de la clasificación internacional de las enfermedades (en adelante CIE). Esta nueva clasificación, conocida como CIE-11 entrará en vigor el uno de enero de $2022^{1}$. La CIE- $11^{2}$ establece que la transexualidad no constituye ninguna enfermedad y se

\footnotetext{
${ }^{1}$ Organización Mundial de la Salud, 18 de junio de 2018, La Organización Mundial de la Salud (OMS) publica hoy su nueva Clasificación Internacional de Enfermedades (CIE-11) (Comunicado de prensa) Disponible en https://www.who.int/es/news-room/detail/17-06-2018-who-releases-new-internationalclassification-of-diseases-(icd-11)

2 Disponible en https://icd.who.int/es/
} 
incluye en un nuevo capítulo "incongruencia de género". De esta manera la OMS ha despatologizado la transexualidad. Cabe destacar en el panorama internacional los Principios de Yogyakarta de 2007 los cuales ponen en relación los Derechos Humanos recogidos en la Declaración Universal de Derechos Humanos de 1948 con la identidad de género ${ }^{3}$. En estos principios se subsume el derecho a la identidad de género en el contenido del derecho a la dignidad, derecho reconocido en el artículo 1 de la Declaración Universal de Derechos Humanos ${ }^{4}$.

En nuestro entorno comunitario, el origen de la regulación jurídica de la transexualidad se encuentra en la Resolución del Parlamento Europeo de 12 de septiembre de 1989 sobre la discriminación de los transexuales y en la Recomendación 1117, de 29 de septiembre de 1989, de Asamblea Parlamentaria del Consejo de Europa, relativa a la condición de los transexuales. Estos instrumentos realizaban una petición a los Estados miembros para aprobar disposiciones sobre el derecho de los transexuales a un procedimiento de cambio de sexo con un contenido mínimo relativo al reconocimiento jurídico del cambio de nombre y sexo en la partida de nacimiento y en el documento de identidad. La regulación de los derechos de este colectivo ha ido completándose con numerosas resoluciones del Parlamento Europeo, y así el último instrumento que ha contemplado la regulación de este colectivo en ámbito europeo, ha sido la Estrategia para la igualdad de las personas LGBTIQ 20202025 de la Comisión Europea ${ }^{5}$. Este instrumento fomentará «el intercambio de las mejores prácticas entre los Estados miembros acerca del modo de introducir legislación y procedimientos accesibles para el reconocimiento jurídico del género con arreglo al principio de autodeterminación y sin límites de edad»

En España la regulación de los derechos del colectivo trans no se encuentra armonizada a nivel estatal. No existe una ley estatal que regule la situación de las personas trans de manera integral, sin embargo, la mayoría de las comunidades autónomas (en adelante, CCAA) ${ }^{6}$ han regulado con mayor o menor amplitud aspectos esenciales para este colectivo. Cada CCAA ha interpretado el derecho a la autodeterminación de género y ha establecido diferentes requisitos para ejercer diferentes derechos ${ }^{7}$.

\footnotetext{
${ }^{3}$ El valor jurídico de esta declaración no es el de un tratado internacional, por lo que sus disposiciones no tienen carácter vinculante para los Estados firmantes.

4 «La orientación sexual o identidad de género que cada persona defina para sí, es esencial para su personalidad y constituye uno de los aspectos fundamentales de su autodeterminación, su dignidad y su libertad».

${ }^{5}$ Disponible

en

https://eur-lex.europa.eu/legalcontent/ES/TXT/PDF/?uri=CELEX:52020DC0698\&from=EN

${ }^{6}$ Castilla-La Mancha, Castilla y León, La Rioja y Asturias, a diferencia del resto de CCAA no tienen regulación para este colectivo.

7 Llamativo son las discrepancias entre algunas legislaciones autonómicas en la definición de persona trans. País Vasco y Canarias exigen ciertos requisitos para que una persona sea considerada trans, mientras que, en el resto de CCAA que regulan los derechos de este colectivo no exigen nada más que la disconformidad interna de la persona entre su sexo morfológico y su sexo sentido para ser considerado trans.
} 
En cambio, sí existe regulación del cambio en la mención registral del sexo para las personas trans, la cual se haya recogida en la Ley $3 / 2007$, de 15 de marzo reguladora de la rectificación registral de la mención relativa al sexo de las personas (en adelante, Ley $3 / 2007)^{8}$.

La Ley 3/2007, vigente actualmente, se ocupa de regular el procedimiento para llevar a cabo el cambio de la mención del sexo en el registro civil. Por tanto, este cuerpo normativo establece los requisitos necesarios para que se acepte este cambio, quién está legitimado para poder iniciar este procedimiento y los efectos de esta rectificación registral. Lo principal de esta Ley 3/2007 es la necesidad de acreditar unos requisitos para la aprobación de la rectificación registral del sexo. Estos requisitos que la persona trans debe acreditar en la actualidad son: diagnóstico de disforia de género y tratamiento hormonal de al menos dos años de duración. En ningún caso deberá acreditar y por tanto someterse la persona trans a una cirugía de reasignación sexual para cambiar el sexo en el registro civil ${ }^{9}$.

Una vez expuesta la normativa actual que regula el colectivo trans se analizarán las disposiciones del borrador de la ley trans relativas al cambio registral y sus posibles implicaciones en la seguridad del tráfico jurídico.

\section{Derecho a la identidad de género (art.5)}

Aunque parece que la principal novedad de este documento es el reconocimiento del derecho a la identidad de género libremente manifestada, establecido así en su art. 5, que establece: «Toda persona tiene derecho al reconocimiento de su identidad de género libremente manifestada, sin la necesidad de prueba psicológica o médica, en los términos previstos en esta ley, sin que pueda mediar discriminación por razón de edad, sexo, origen racial o étnico, nacionalidad, religión, orientación sexual, expresión de género, características sexuales, discapacidad, enfermedad, estado serológico, lengua, clase social, migración, situación administrativa o cualquier otra condición personal o social». No es menos cierto que este derecho ya había sido reconocido por la mayoría de las legislaciones autonómicas que habían abarcado los derechos de este colectivo ${ }^{10}$.

Por lo que el hecho de que se reconociese en ámbito estatal algo que se reconoce en la mayoría de las autonomías del estado no viene a romper ningún molde ni a ser algo tan novedoso. Lo que sí protagoniza la principal novedad de este borrador es la aplicación y el ejercicio de este derecho a la identidad de género en la rectificación registral de la mención del sexo, la cual se analizará en profundidad a continuación.

\footnotetext{
${ }^{8}$ BOE núm.65, 16 de marzo de 2007.

${ }^{9}$ Esta mención expresa terminaba así con el criterio jurisprudencial anterior a la entrada en vigor de esta norma que solicitaba la acreditación de la cirugía de reasignación sexual para aprobar la rectificación registral basándose en la necesidad de que el Registro Civil acreditara un hecho cierto.

${ }^{10}$ Así ocurre en todas leyes de las CCAA que han legislado sobre esta materia, excepto en la ley del País Vasco y en la de Galicia.
} 


\section{Rectificación registral de la mención relativa al sexo de las personas (arts. 9 a 18)}

El título II de este borrador contiene la regulación relativa al cambio de la mención relativa al sexo en el Registro Civil. Modificaría así la Ley 3/2007 y siendo este título realmente el mayor objeto de debate ya que elimina el vigente art. 4 de la Ley 3/2007 donde se establecen los requisitos para que se apruebe el cambio en la mención relativa al sexo.

El procedimiento que sostiene este borrador para el cambio en la mención registral del sexo se basa en el derecho de autodeterminación de género. Este derecho ya ha sido reconocido como principio rector en las legislaciones sobre los derechos del colectivo trans por la mayoría de CCAA que han regulado sobre este campo. Este derecho a la autodeterminación de género es definido en las actuales legislaciones autonómicas como «el reconocimiento de su identidad de género, libremente determinada» ${ }^{11}$. La exposición de motivos de la Ley $2 / 2014$, de 8 de julio, integral para la no discriminación por motivos de identidad de género y reconocimiento de los derechos de las personas transexuales de Andalucía ${ }^{12}$ establece: «En la persona imperan las características psicológicas que configuran su forma de ser y se ha de otorgar soberanía a la voluntad humana sobre cualquier otra consideración física. La libre autodeterminación del género de cada persona ha de ser afirmada como un derecho humano fundamental».

Así, este derecho de autodeterminación del género es el principio sobre el que se basa este borrador, estableciendo el derecho a cambiar la mención registral relativa al sexo solo manifestando la voluntad de la persona y sin que un tercero tenga que acreditar situación de transexualidad a través de informes o tratamientos médicos.

\subsection{Legitimación (art. 9)}

El artículo 9 del documento estipula que solo las personas físicas con nacionalidad española podrán optar a este cambio en el registro civil, cuestión invariable en relación a la vigente Ley $3 / 2007^{13}$. Lo que sí es todo un giro respecto a la vigente Ley 3/2007 es la legitimación para iniciar este procedimiento reconocida a todas las personas físicas independientemente de su edad. El art. 9 modula la manera de iniciar el procedimiento del cambio registral dependiendo de la edad, estipulando así tres escalones:

- Estarán legitimados para iniciar el procedimiento los mayores de 16 años pudiendo solicitar el cambio por sí mismos. El requisito que se establece en este escalón de edad es tener capacidad suficiente.

\footnotetext{
11 Ley 8/2020, de 11 de noviembre, de Garantía de Derechos de las Personas Lesbianas, Gais, Trans, Transgénero, Bisexuales e Intersexuales y No Discriminación por Razón de Orientación Sexual e Identidad de Género.

12 BOJA núm. 139, 18 de julio de 2014.

13 Es una cuestión técnica, no se puede cambiar ninguna mención registral a las personas que no se encuentran inscritas en el Registro Civil.
} 
- Estarán legitimados para iniciar el procedimiento los mayores de 12 años y menores de 16 años a través de sus representantes legales o por sí mismos con el consentimiento de los representantes.

- Estarán legitimados para iniciar el procedimiento los menores de 12 años y las personas con capacidad de obrar modificada judicialmente a través de sus representantes legales.

En previsión de desacuerdo entre los representantes legales o entre estos y el menor, el documento establece en su art. 9.4 que los menores de 16 años podrán iniciar el procedimiento de rectificación registral a través de uno solo de los representantes y en su caso, se procederá al nombramiento de un defensor judicial de acuerdo al art.300 del CC.

Es este artículo, junto a la eliminación de los requisitos médicos exigidos para que la autoridad competente apruebe la rectificación registral el generador del ruido mediático. Por ello, a continuación, se analizan sus principales disposiciones.

\subsubsection{Los menores independientemente de la edad podrán cambiar su mención registral del sexo}

El art. 1 de la vigente Ley 3/2007 relativo a la legitimación, establece que podrá iniciar el procedimiento para la rectificación registral de la mención relativa al sexo los mayores de edad. Este artículo fue declarado inconstitucional por el TC en su sentencia n099/2019, de 18 de julio de 2019. Sin embargo, matizaba el TC que la inconstitucionalidad se desprende de la prohibición a aquellos menores que se encuentren en situación estable de transexualidad y tengan suficiente madurez. Es decir, que el TC establece que los mayores de edad están legitimados para iniciar el procedimiento de rectificación registral y así también los menores que tengan una situación estable de transexualidad y madurez suficiente.

En el borrador analizado se elimina por completo esta apreciación del TC. No hay estipulación alguna donde los menores de edad deban acreditar suficiente madurez y mucho menos una condición estable de transexualidad para cambiar la mención relativa al sexo. Únicamente deben querer cambiar su sexo en el RC para hacerlo (dependiendo de la edad a través de sus representantes o con su consentimiento).

Es cierto que el TC no definió quién y cómo se debía acreditar la suficiente madurez ni la condición estable de transexualidad, lo que abría un panorama de inseguridad jurídica para los menores, pudiendo dar lugar a la arbitrariedad. El encargado puede denegar o aceptar el cambio del menor a tenor de su juicio, dependiendo de si, a su mejor entender, aprecia o no suficiente madurez.

Sin embargo, el borrador establece que para el cambio registral de los mayores de 16 años deberán "tener capacidad suficiente". Este requisito también se encuentra estipulado en la vigente Ley $3 / 2007$. Pero, ¿a qué se refiere esta capacidad suficiente? Este requisito puede interpretarse como el hecho de gozar del suficiente y necesario juicio para realizar la solicitud de la modificación registral. No excluye de manera expresa a las personas con la capacidad de obrar modificada judicialmente, 
la norma no habla de que se deba disponer de una capacidad plena sino simplemente de capacidad suficiente para realizar este trámite. En el caso de las personas con la capacidad de obrar modificada judicialmente habrá que estar a la sentencia de modificación de la capacidad para observar si la persona dispone de capacidad para realizar este proceso o no. Pero si no existe sentencia alguna, ¿quién debe valorar si la persona que solicita el cambio registral del sexo tiene capacidad suficiente? ¿será el propio encargado del RC? ¿y bajo qué criterio podría el encargado del RC denegar el cambio? ¿Podría hallarse en este requisito un obstáculo para el libre cambio de la mención registral del sexo en el RC que persigue este borrador? ¿y qué ocurre con las personas que tienen reconocido un trastorno psiquiátrico? El documento estipula en su art. 26 que estos trastornos no serán obstáculos para entender inválido el consentimiento de la persona trans que solicitan el cambio registral del sexo. Esto supone una contradicción en el mismo cuerpo normativo dando lugar a arbitrariedad y a numerosas interpretaciones por la persona encargada de aceptar o rechazar el cambio en el registro que no podrá valerse de requisitos concretos sino de su mejor entender.

A pesar de las carencias en aplicación práctica del fallo de la sentencia, el TC sí que abordó un aspecto esencial que no parece tener en consideración este borrador: el interés superior del menor. La cuestión de restringir a los menores de edad la posibilidad de cambiar su mención relativa al sexo en el RC obedece a la necesidad de protección de la persona menor de edad, objetivo de relevancia similar al ejercicio de los derechos fundamentales ya que la protección del interés superior del menor es un mandato recogido en el artículo 39 de la CE. La restricción persigue un objetivo constitucionalmente legítimo, sin embargo, el TC modula esta restricción en el juicio de proporcionalidad, entendiendo que no es una medida necesaria ya que existe una forma de proteger el interés superior del menor de una manera menos restrictiva. Esta manera es precisamente permitir iniciar el procedimiento de modificación registral a los menores siempre y cuando tengan una situación estable de transexualidad y capacidad suficiente.

En España, los menores de edad al igual que los mayores de edad son titulares de los derechos fundamentales consagrados constitucionalmente y así se establece en la Ley Orgánica 1/1996, de 15 de enero, de Protección Jurídica del Menor, de modificación parcial del Código Civil y de la Ley de Enjuiciamiento Civil (en adelante, LO 1/1996) ${ }^{14}$. Esta ley ha sido modificada por la Ley Orgánica 8/2015, de 22 de julio, de modificación del sistema de protección a la infancia y a la adolescencia (en adelante, LO 8/2015) ${ }^{15}$.

La LO 1/1996 regula el interés superior del menor como un valor primordial en todas las decisiones relativas a los menores y como un derecho sustantivo ${ }^{16}$. El menor tiene

\footnotetext{
14 BOE núm. 15, 17 de enero de 1996.

15 BOE núm. 175, 23 de julio de 2015.

16 SANCHEZ FREYRE, J., "La mayoría de edad como requisito para la rectificación registral del sexo y el nombre: una cuestión de derechos fundamentales", Revista sobre la infancia y la adolescencia, núm.14, 2018, págs. 39-52.
} 
derecho a que se evalúen sus mejores intereses y que estos sean ponderados cuando haya otros intereses en conflicto en el momento de adoptar una medida que le afecte. Es un principio general de finalidad interpretativa, es decir, si una disposición jurídica puede interpretarse de varias formas, se deberá optar por la interpretación que responda de mejor manera a los intereses del menor.

La finalidad del principio del interés del menor es asegurar su desarrollo integral respetando todos sus derechos. A lo largo de la LO 8/2015 se menciona la identidad sexual del menor como criterio general a tener en cuenta para la interpretación y aplicación de disposiciones y como elemento general para ponderar situaciones. Así en el segundo apartado de su artículo 2, se regula como criterio general a la hora de interpretar y aplicar una disposición la preservación de la identidad sexual del menor. Aunque no se trata de reconocer de forma expresa que los menores tienen derecho a la identidad sexual, este derecho se encuentra implícito en la exposición de este artículo.

La doctrina constitucional por la que la restricción legal para iniciar el proceso de cambio de sexo en el RC a los menores de edad sin suficiente capacidad y sin situación estable de transexualidad persigue la protección del interés superior del menor, cabría concluir que el hecho de que el borrador de la ley trans no estipule ningún requisito para que un menor de edad cambie su mención registral relativa al sexo podría vulnerar el interés superior del menor.

Podría ser más efectivo seguir el mandato constitucional iniciado en la sentencia 99/2019 y permitir que los menores de edad sí puedan iniciar el cambio en la mención relativa al sexo en el RC, pero fijando un procedimiento detallado y concreto que asegure que se cumple con la protección del interés superior del menor. El cambio registral en la mención relativa al sexo no es una acción trivial ya que el menor no solo cambiará su mención registral sino que solicitará la expedición de un nuevo DNI acorde a su nueva mención registral, lo que marcaría la identificación del menor a partir de este momento con otro sexo y esta nueva identificación será mostrada en actividades habituales de la vida como, por ejemplo, solicitar la expedición de certificados académicos, búsqueda de empleo, viajar o ingresar en algún recinto que exija identificación, participar en competiciones deportivas o incluso en concursos públicos en los que se requieren pruebas físicas, que habitualmente exigen distintas marcas en función del sexo (policía, bombero, ejército...).

¿Y qué ocurre si un menor quiere cambiar su mención registral del sexo, pero cuando alcanza la edad adulta se arrepiente? ¿Se puede cambiar de nuevo el sexo? El documento no indica nada respecto a la revocabilidad de la decisión sobre el cambio de sexo en el registro. Pero si el cambio de la mención relativa al sexo se basa en el derecho a la autodeterminación del sexo libremente, cabe entender que las personas podrán cambiar su mención relativa al sexo tantas veces como ellos quieran, ya que no se prohíbe en el documento e incluso la imposición de irrevocabilidad podría ir en contra de los principios que marcan el propio documento. 


\subsubsection{Los menores de más de 16 años no necesitan representantes legales para cambiar su mención registral relativa al sexo}

Algo muy significativo de esta disposición es que los menores de 16 y 17 años no necesitarán ningún consentimiento por parte de sus representantes legales, ni acreditar madurez suficiente, lo que les iguala a los mayores de edad. Este documento parece romper con el artículo 322 del CC que estipula la mayoría de edad como la barrera para alcanzar la capacidad de obrar plena ${ }^{17}$. Sin embargo, el acto que aquí se desarrolla al cambiar el sexo en el RC no es una actividad patrimonial para la cual es imprescindible las reglas de la capacidad de obrar establecida en el $\mathrm{CC}$, sino que se trata del ejercicio del derecho fundamental a la identidad de género reconocido en el borrador y por el TC.

Los menores son titulares de los derechos fundamentales al igual que las personas mayores de edad y el ejercicio de los derechos fundamentales, a diferencia de su titularidad, hace referencia a la capacidad del individuo para disfrutar de un ámbito de libertad garantizado por el derecho. La determinación de un criterio para reconocer la capacidad para ejercer los derechos fundamentales dependerá de las circunstancias concretas de cada persona. Constitucionalmente parece que lo único que se puede exigir para el ejercicio autónomo de un derecho fundamental es madurez suficiente como para expresar una voluntad de autorrealización propia ${ }^{18}$.

Así, el artículo 162 del CC establece que los que ostenten la patria potestad serán los representantes de los menores no emancipados exceptuando, los actos relativos a los derechos de la personalidad que el hijo pueda ejercitar por sí mismo, de acuerdo con su madurez. No cabe duda que el derecho a la identidad de género se enmarca en los derechos de la personalidad, por lo que podría concluirse que los menores de edad serían capaces de regir sus decisiones relativas a su identidad sexual ${ }^{19}$.

Sin embargo, esta ampliación de no exigir consentimiento alguno o participación de los representantes legales a los menores entre 16 y 17 años, se separa del criterio constitucional de permitir su cambio en la mención registral del sexo siempre y cuando acreditasen suficiente madurez. En este borrador solo se exige capacidad suficiente de manera igualitaria tanto para mayores de edad como para menores de más de 16 años sin exigencias específicas para estos menores sobre su madurez para ejercer el derecho fundamental por sí mismos.

\subsubsection{No hay que acreditar tratamiento hormonal ni diagnóstico de disforia de género} (art. 12)

Además de la edad, el otro punto controvertido de este borrador es que no es necesario acreditar a través de instrumentos médicos la situación de transexualidad para cambiar la mención relativa al sexo en el RC. Así se establece en su art.12.1:

\footnotetext{
17 «El mayor de edad es capaz para todos los actos de la vida civil, salvo las excepciones establecidas en casos especiales por este Código».

18 ALÁEZ CORRAL, B., Minoría de edad y derechos fundamentales. Tecnos. Madrid, 2003.

19 SANCHEZ FREYRE, J., op cit., págs. 39-52
} 
«La solicitud de rectificación registral de la mención de sexo no precisa de más requisitos que la declaración expresa, de la persona interesada o de sus representantes legales, de acuerdo con lo establecido en esta ley, indicando el nombre propio, en su caso, y sexo registral con los que se siente identificada, a fin de acreditar la voluntad de la persona interesada, así como los datos necesarios de la inscripción que se pretende rectificar, y el número del documento nacional de identidad».

La mayoría de las CCAA que han regulado en esta materia basaban su legislación en el derecho a la autodeterminación de género, lo que implica la no necesidad de acreditar la situación de transexualidad para considerarse parte del género sentido y no del morfológico. De esta manera, el borrador parece aunar todas estas regulaciones bajo la eliminación de los requisitos para la rectificación registral. Si la mayoría de CCAA reconocen que una persona es transexual solo por el mero hecho de sentir disconformidad entre el sexo biológico y el sentido, este borrador comprende que no puede solicitarse a esa misma persona que acredite ningún requisito para que se reconozca esa situación de transexualidad en la identificación registral. Igualmente parece más acorde a los postulados internacionales de los Principios de Yogyakarta y a la CIE-11, que ha despatologizado la transexualidad.

Ahora bien, sigue el art.13 en su apdo. 2: «El ejercicio de este derecho en ningún caso podrá estar condicionado a la previa exhibición de informe médico o psicológico alguno, ni a la previa modificación de la apariencia o función corporal de la persona a través de procedimientos médicos, quirúrgicos o de otra índole, sin perjuicio del derecho de la persona interesada a hacer uso de tales medios». Esto significa que una persona con un apariencia y función corporal acorde al género masculino podrá cambiar su mención registral relativa al sexo y que en su identificación conste como sexo femenino. En la vida cotidiana son muchas las situaciones en las que la confusión ocasionada por la discordancia entre el sexo recogido en el documento de identificación y el aspecto externo podría provocar cierta inseguridad jurídica frente a terceros. Por ejemplo, en cualquier situación en la que se requiera que la persona exhiba su DNI (cuando va a coger un avión, cuando va a abrir una cuenta bancaria o a hacer cualquier gestión administrativa). Y qué ocurre cuando el sexo es el criterio estipulado para organizar ciertas actividades, por ejemplo: ¿qué aseos públicos debe utilizar una persona con identificación femenina, pero aspecto masculino? en un concurso público para profesiones donde se exigen distintas marcas dependiendo del sexo, ¿en cuáles se debe inscribir una persona con apariencia masculina y sexo femenino? No hay respuesta para estas actividades habituales donde el sexo sigue siendo un criterio de distinción, por lo que el texto de la futura ley tendría que resolver estas cuestiones.

¿Y en el ámbito deportivo? ¿Puede una persona con físico femenino sin alteración hormonal, pero con identificación masculina participar en las competiciones masculinas? A esta pregunta, no escasa de repercusión mediática, sí ha dado respuesta este borrador en su art. 39 que establece: «En las prácticas, eventos y competiciones deportivos se considerará a las personas que participen atendiendo a 
su sexo registral, sin que puedan realizarse en ningún caso pruebas de verificación del sexo». Sin embargo, el objetivo de igualdad que pretende este artículo 39 para estas competiciones deportivas en las que se diferencia por sexo a causa de capacidades físicas que hacen diferente el sexo masculino del femenino, provocaría el resultado contrario, la desigualdad manifiesta entre los participantes que impediría una competición justa.

Además, la falta de coincidencia entre la apariencia externa y el sexo inscrito ¿no provoca este hecho cotidiano dificultades en la identificación? Aunque a priori los problemas de identificación puedan suponer una traba a la falta de concordancia entre el sexo registral y el aspecto físico, parece que el sexo pierde cierta influencia de acuerdo al artículo 6 de la Ley 20/2011, de 21 de julio, del Registro Civil ${ }^{20}$. Este artículo regula el código personal, el cual trata de una secuencia alfanumérica imputada por el sistema informático para el documento nacional de identidad registrada de manera individual en la primera inscripción ${ }^{21}$.

¿Y qué ocurre con las leyes en las que son clave el sexo de la persona para su aplicación? Así, la Ley Orgánica 1/2004, de 28 de diciembre, de Medidas de Protección Integral contra la Violencia de Género (en adelante, LO 1/2004) ${ }^{22}$ y la Ley Orgánica $3 / 2007$, de 22 de marzo, para la igualdad efectiva de mujeres y hombres (en adelante, LO 3/2007 de 22 de marzo) ${ }^{23}$. Para estas normas reviste carácter esencial el sexo de las personas. De hecho, el borrador en su art. 14 indica que el cambio en la mención registral relativa al sexo no alterará la titularidad de los derechos y obligaciones jurídicas que pudieran corresponder a la persona con anterioridad a la inscripción del cambio registral, en particular a efectos de lo establecido en la Ley Orgánica 1/2004, de 28 de diciembre, de Medidas de Protección Integral contra la Violencia de Género.

La disposición indica con anterioridad, pero qué ocurriría en el siguiente supuesto: en un matrimonio de personas del mismo sexo masculino, existe violencia doméstica y uno de los cónyuges se encuentra inmerso en un procedimiento penal, por ello, durante este periodo de tiempo, el cónyuge víctima de esta violencia, cambia su sexo en el RC ¿podría esta persona ser beneficiario de los derechos recogidos en la LO $1 / 2004$ ? Es más, la picaresca está servida, en el mismo supuesto, el agresor podría cambiar igualmente su sexo en el RC ya que solo es necesario su declaración de pertenencia al otro sexo y así no ser de aplicación la LO 1/2004. Y debido, a que no se prohíbe la revocabilidad de la mención registral del sexo, es posible que posteriormente a terminar el procedimiento penal, puedan volver a cambiar su sexo sin inconveniente.

\footnotetext{
20 BOE núm. 175, 22 de julio de 2011.

21 «A cada registro individual abierto con la primera inscripción que se practique se le asignará un código personal constituido por la secuencia alfanumérica que atribuya el sistema informático vigente para el documento nacional de identidad».

22 BOE núm. 313, 29 de diciembre de 2004.

${ }^{23}$ BOE núm. 71, 23 de marzo de 2007.
} 


\subsection{Los menores podrán cambiar su nombre de acuerdo exclusivamente a su identidad de género (art. 17)}

El artículo 17 establece: «Las personas trans menores tienen derecho a obtener la inscripción registral del cambio de nombre para que este se corresponda con su identidad de género, sin necesidad de rectificar la mención relativa al sexo. La solicitud de inscripción del cambio de nombre será atendida en el Registro Civil, con el mismo procedimiento y requisitos que los establecidos en este título para la rectificación registral de la mención relativa al sexo».

Esta disposición tiene su germen en la Instrucción del DGRN del 23 de octubre de 2018 sobre el cambio de nombre en el Registro Civil de personas transexuales. La DGRN establecía así que los menores de edad podrían cambiar su nombre de acuerdo a su sexo sentido y no al morfológico inscrito independientemente de la edad de éstos. Para ello, los representantes legales del menor podrán declarar ante el encargado del registro o mediante documento literal que: "el menor siente como propio el sexo correspondiente al nombre solicitado de forma clara e incontestable". Este borrador en su art.17 parece haber tomado en consideración esta Instrucción ya que no existen diferencias llamativas entre ellas.

Esto originará la discrepancia entre el nombre y el sexo del menor, es decir, el nombre podría identificar el sexo femenino mientras que el sexo sería masculino. La DGRN aceptaba esta controversia provocada por la Instrucción y solventaba dicha incoherencia en la prevalencia del sexo psicológico al morfológico inscrito, concluyendo que finalmente no existía tal contradicción, ya que el nombre responde al sexo sentido que es el verdadero sexo, negando de esta manera cualquier valor jurídico el sexo inscrito.

La nueva ley del $\mathrm{RC}$ ha eliminado de su articulado la prohibición de que el nombre induzca error en cuanto al sexo, pero sí que mantiene el art. 51 de la Ley 20/2011 la prohibición de elegir un nombre que haga confusa la identificación. ¿Se puede considerar confuso elegir un nombre que no es acorde con el sexo? ¿y qué no sea acorde con la apariencia física? Si el nombre no se identifica con el sexo ni con la apariencia física, pierde todo valor identificador lo que en último término podría interpretarse como una vulneración del art. 50 de la Ley 20/2011 «Las personas son identificadas por su nombre». Además, podría suponer el incumplimiento del art. 24.2 del Pacto Internacional de Derechos Civiles y Políticos ${ }^{24}$ que reconoce el derecho al nombre y en último término atentar contra la dignidad de la persona. Quizá el futuro reserve al nombre una posición fuera de la regulación jurídica, relegando su relevancia a la altura de los actuales apodos, y las personas deban ser inscritas en el Registro solo y exclusivamente con un código. Pese a lo que pueda deparar el futuro, en la actualidad el nombre dota de identidad y es un bien de la personalidad, formando parte del derecho a la propia imagen y por tanto afectando a la vida externa

\footnotetext{
24 «Todo niño será inscrito inmediatamente después de su nacimiento y deberá tener un nombre».
} 
de la persona que lo sostiene haciendo efectivas las relaciones sociales y jurídicas ${ }^{25}$. A mayor abundamiento, el nombre otorga existencia legal y permite a su vez ejercitar otros derechos de la personalidad, como el derecho al honor, a la propia imagen y a la intimidad.

\subsection{La mención registral relativa al sexo puede desaparecer}

El art. 13 del borrador reza así «El Ministerio del Interior adoptará las medidas necesarias para que los documentos oficiales de identificación puedan omitir, a petición de la persona interesada, la mención relativa al sexo». La disposición implica en la práctica la desaparición de la mención relativa al sexo para la identificación de las personas y esto supone cuestionar si es esencial esta identificación por sexo y qué consecuencias podrían acarrear su desaparición. Actualmente, según el art.16726 y 170.2 del Decreto de 14 de noviembre de 1958 por el que se aprueba el Reglamento de la Ley del Registro Civil ${ }^{27}$, el sexo se inscribe desde el momento de nacimiento, lo que no entraría en contradicción con esta disposición ya que se trata de un cambio a posteriori. Sin embargo, si finalmente desapareciese el sexo como parte esencial de la identificación de la persona sí que habría que modificar dicho artículo.

Anteriormente el hecho de ser mujer u hombre influía en la capacidad de obrar, pero en la actualidad pertenecer a uno u otro sexo no merma la capacidad de obrar de ninguno de los dos géneros. Tampoco resulta necesaria la determinación del sexo a efectos de la capacidad para contraer matrimonio desde la Ley 13/2005, de 1 de julio, por la que se modifica el Código Civil en materia de derecho a contraer matrimonio ${ }^{28}$. También se modificó la relevancia del sexo en la filiación posibilitando la adopción por dos personas del mismo sexo. El sexo ha ido perdiendo relevancia en la identificación, no obstante, todavía la determinación del sexo tiene alguna relevancia jurídica como se ha podido observar en las dos leyes anteriormente mencionadas, la LO 1/2004, de 28 de diciembre y la LO 3/2007 de 22 de marzo. Además de su relevancia en otros planos que pueden afectar al desarrollo de la persona (competiciones deportivas, oposiciones con pruebas físicas...).

En ambos cuerpos normativos es esencial la distinción por sexo. Si desaparece la identificación por sexo no podría aplicarse ninguna de estas leyes, no podría apreciar ningún juez violencia de género, ya que las dos personas no tendrían en su identificación mención alguna a ningún género. ¿Y qué ocurriría en los sistemas penitenciarios? Estos centros están divididos por sexo, si este se elimina, ¿tendrían

\footnotetext{
25 BERCOVITZ RODRÍGUEZ-CANO, R., Manual de derecho civil. Derecho Privado y Derecho de la persona. 5a Edic. Bercal S.A. Madrid, 2011, págs. 81-83

26 «En el parte de nacimiento, además del nombre, apellidos, carácter y número de colegiación de quien lo suscribe, constará con la precisión que la inscripción requiere la fecha, hora y lugar del alumbramiento, sexo del nacido y menciones de identidad de la madre, indicando si es conocida de ciencia, propia o acreditada, y en este supuesto, documentos oficiales examinados o menciones de identidad de persona que afirme los datos, la cual, con la madre, firmará el parte, salvo si esta no puede o se opone, circunstancia que también se hará contar».

27 BOE núm. 296, de 11 de diciembre de 1958.

${ }^{28}$ BOE núm. 157, 2 de julio de 2005.
} 
que pedir una declaración expresa a cada uno de los internos para conocer cuál es su identidad de género? ¿Y si alguno se niega a declarar cuál es su sexo sentido? De igual forma ocurriría con los centros educativos que separan por sexo sus aulas, se hallarían en la misma situación y con el mismo problema que los centros penitenciarios. $Y$ otro campo donde es esencial esta identificación es en el ámbito deportivo, donde la organización de torneos o campeonatos deberá hacerse de acuerdo a otros parámetros distintos al sexo si este desapareciese.

Ahondando en la relevancia que puede alcanzar la identificación por sexo, se haya el derecho canónico donde es esencial la identificación por sexo para ser reconocido un matrimonio válido por la autoridad eclesiástica. ¿Qué ocurriría si las autoridades eclesiásticas no pudieran comprobar el sexo de los cónyuges? No podrían autorizar el matrimonio.

El borrador en su Disposición Adicional Segunda establece «El Gobierno remitirá en el plazo de un año a las Cortes Generales un informe sobre las eventuales modificaciones normativas a emprender derivadas, en su caso, del reconocimiento del género no binario», así incluye no solo la posibilidad de la desaparición del sexo como rasgo identificador, sino la posibilidad de registrar un tercer sexo ¿a las personas que se registrarán con ese tercero sexo, en algún caso les sería de aplicación la LO 1/2004, de 28 de diciembre y la LO 3/2007 de 22 de marzo? ¿Qué ocurriría en el ámbito deportivo donde existen competiciones deportivas separadas para hombres y mujeres?

Parece que en la actualidad $y$, aunque por motivos muy distintos a los que hicieron necesario en el pasado la determinación del sexo, se entiende justificada la identificación sexual, por lo que la propuesta de eliminar la mención relativa al sexo podría llegar a ocasionar numerosos problemas de inseguridad jurídica y orden público.

\subsection{Los extranjeros también pueden adaptar su documentación (art. 18)}

Una novedad que contempla este borrador y que la vigente Ley 3/2007 no reconocía, es la posibilidad de que los extranjeros con residencia legal ${ }^{29}$ en España puedan adaptar su documentación de acuerdo a su identidad de género. Para que estas personas puedan acceder al cambio del sexo se estipula en el art.18 los siguientes requisitos «que no pudieren o no hubieren rectificado la mención registral relativa al sexo o el cambio de nombre en su país de origen y que acrediten la notoriedad, bien de la imposibilidad legal o de hecho de llevarlo a efecto, bien de que ello signifique riesgo para su propia vida o integridad».

Nada indica la disposición sobre cómo se acreditará con notoriedad la imposibilidad de realizar el cambio en su país de origen si no existe en el mismo una ley que prohíba esta rectificación registral.

\footnotetext{
29 Ley Orgánica 4/2000, de 11 de enero, sobre derechos y libertades de los extranjeros en España y su integración social.
} 
Esta ampliación para que los extranjeros puedan modificar su tarjeta de residencia encuentra su origen en la proposición de ley sobre la protección jurídica de las personas trans y el derecho a la libre determinación de la identidad sexual y expresión de género presentada por el Grupo Parlamentario Confederal de Unidos Podemos-En Comú Podem-En Marea el 2 de marzo de 2018 y en la resolución de 24 de enero de 2005 de la DGRN (RJ 2005/1954) donde se admite la competencia de los tribunales españoles de cambiar el sexo de un extranjero transexual con residencia en España aun siendo imposible dicha rectificación en su país de origen.

\section{4. ¿Cómo se regula esta cuestión en los países de nuestro entorno?}

Dentro del entorno comunitario hay una amalgama de regulaciones sobre el cambio de la mención registral relativa al sexo que difieren entre ellas. Desde los países que reconocen el derecho a la autodeterminación de género libre sin necesidad de acreditar ningún requisito a aquellos en los que está prohibido cambiar el sexo en la mención registral.

Dinamarca ha sido el país de la Unión Europea pionero en legislar de acuerdo al principio de autodeterminación del género libre sin necesidad de acreditar ningún tipo de requisito médico o psicológico, lo que en último término conlleva la total despatologización de la transexualidad. Así en 2014 Dinamarca reformó su ley del Registro Civil, dotando a las personas con disconformidad entre su sexo sentido y su sexo morfológico del derecho de rectificar su mención relativa al sexo con la simple declaración expresa convirtiéndose en un mero trámite administrativo que nadie tiene que valorar. Sin embargo, Dinamarca limita esta posibilidad a los mayores de 18 años y establece un periodo de seis meses desde la solicitud para que la persona ratifique su decisión y así la rectificación se haga definitiva.

Otros países europeos se han sumado a la pionera Dinamarca, así Malta e Irlanda en 2015, Bélgica en 2017 y Luxemburgo y Portugal en 2018.

La legislación de Malta e Irlanda, al igual que este proyecto, permite la rectificación registral sin acreditar ningún informe médico o tratamiento hormonal o quirúrgico, solo la simple manifestación será necesaria para adaptar el sexo inscrito con el sexo sentido. Ahora bien, esta posibilidad de rectificación registral en ambos países es solo aplicable a mayores de 18 años. En Malta los menores de 16 y 17 años, podrán iniciar este procedimiento administrativo a través de sus representantes legales, pero verán sometida su voluntad a la decisión final de un juez de acuerdo a su madurez. En Irlanda, los menores de 16 y 17 años verán sometida su identidad sexual a requisitos médicos que deberán acreditar (informe psiquiatra e inicio de tratamiento hormonal), además del consentimiento de sus representantes legales ${ }^{30}$.

Malta ha ido más allá incluyendo la posibilidad de no registrar ningún sexo, dando visibilidad al sexo no binario y la posibilidad de no registrar el sexo en el momento del nacimiento, a la espera de que se determine por la persona.

\footnotetext{
${ }^{30}$ Disponible en https://data.oireachtas.ie/ie/oireachtas/act/2015/25/eng/enacted/a2515.pdf
} 
Bélgica mantiene la libertad de cambiar el sexo registral sin acreditar requisitos, aunque estipula que podrá ser rechazado por ser contrario al orden público. De igual forma, esta rectificación registral del sexo a través de la manifestación expresa de cambiarlo es solo aplicable a los mayores de 18 años. Los menores de 16 años no podrán acceder a esta rectificación, y los menores entre 16 y 17 años necesitarán acreditar suficiente madurez a través de un informe psiquiátrico ${ }^{31}$.

El siguiente país que se estrenó en el ejercicio del derecho a la autodeterminación de género libre fue Luxemburgo. Al igual que sus homólogos, legisló el derecho a cambiar la rectificación registral del sexo solo con la condición de que la persona argumentase su decisión sin necesidad de acreditar ningún requisito médico ${ }^{32}$. A propósito de los menores de edad, estos podrían acceder a este cambio, pero con consentimiento de sus representantes legales ${ }^{33}$.

El último país de la Unión Europea que se ha sumado a legislar de acuerdo a la no imposición de requisitos médicos ha sido Portugal, que establece el derecho de los mayores de edad de rectificar su mención relativa al sexo sin necesidad de acreditar tratamiento hormonal o informe médico. Ahora bien, restringe a los menores de 16 años esta posibilidad y los menores de 16 y 17 años deberán realizar este cambio a través de sus representantes legales y tendrán que aportar un informe psiquiátrico.

En contra de lo habitual, Alemania no es pionera y se resiste a modificar su ley trans en vigor desde 1981. Alemania exige requisitos para modificar la mención del sexo en el registro, sin embargo, al contrario que en España no son requisitos médicos, no hay obligación de someterse a un tratamiento hormonal, sino que la persona que quiere realizar el cambio de sexo en el registro deberá acreditar que ha vivido durante tres años de acuerdo al sexo sentido y no al morfológico. Además, la última palabra la tendrá un juez por lo que no se trata de un procedimiento administrativo. En Francia igualmente el proceso está judicializado y no tiene carácter administrativo.

En el otro extremo se hayan Rumanía, Bulgaria, Lituania y Letonia donde no existe procedimiento posible para modificar la mención relativa al sexo en los registros por el colectivo trans.

La vigente Ley 3/2007 de España encuentra similitudes con las legislaciones italiana, polaca o finlandesa. Estos países, al igual que España actualmente requieren de informes médicos y tratamientos hormonales para aprobar la rectificación del sexo registral de las personas trans.

\footnotetext{
${ }^{31}$ Disponible en https://www.lachambre.be/FLWB/PDF/54/2403/54K2403001.pdf

32 Esta argumentación puede entenderse como exigencia de requisito, ya que en su ley establece la necesidad de que la persona trans pruebe que lleva un periodo de tiempo suficiente viviendo de acuerdo a su sexo sentido. F577B2A27D13A3FD033A75DB1501A6D3D710008EC05A996E6092C2B9008C0126B68E259B6F2D \$203F 5C9D2B447C2306AAC079947B3FEC
} 
No parece que, en caso de aprobarse este borrador, sea una ley demasiado pionera en el entorno europeo de acuerdo al reconocimiento del derecho a la autodeterminación de género, sin embargo, la posibilidad de que los menores entre 16 y 17 años puedan realizar este cambio sin participación alguna de sus representantes legales y sin acreditar la suficiente madurez sí parece ser bastante «innovador».

\section{Medidas en el ámbito sanitario}

El borrador trans pretende ser una ley integral regulando la situación de las personas trans en todos los ámbitos y unificando así las numerosas leyes de las CCA. Así, establece medidas en el ámbito sanitario, educativo, laboral, sistema penitenciario y deportivo. A tenor de que el ámbito que adquiere mayor relevancia es el sanitario, se analizan sus disposiciones más controvertidas.

La primera medida que estipula este borrador es la inclusión en la cartera de servicios comunes del Sistema Nacional de Salud de la atención sanitaria específica a las personas trans en su art.27.134, lo que homogenizaría las diferentes coberturas sanitarias que ofrecen las CCAA en la actualidad a las personas trans.

Parece que el borrador peca en su objetivo unificador de las legislaciones autonómicas en cuanto al tratamiento hormonal en menores. En su art. 27.2 no establece edad a la cual se puede empezar el tratamiento hormonal pero sí indica «Se informará a la persona menor y a sus representantes legales sobre la posibilidad de posponer o reducir la medicación, respetándose en todo caso la decisión de la persona interesada». ¿Esto significa que el consentimiento lo otorga siempre el menor? De acuerdo a la Ley $41 / 2002$ en su artículo 8 donde se regula el consentimiento informado, este consentimiento es otorgado de manera libre y voluntaria por el afectado. En el caso de los menores de edad que no son capaces intelectual y emocionalmente de comprender el alcance de la intervención, no serán ellos quien otorguen el consentimiento informado, sino que serán sus representantes legales quienes deben otorgar el consentimiento, oída su opinión. De igual manera ocurre con los menores emancipados o mayores de 16 años que quieran comenzar con el tratamiento hormonal y corra peligro grave su vida según el criterio del facultativo o carezcan de suficiente madurez para comprender el alcance de la intervención, prestando en este caso el consentimiento el representante legal. Cabría concluir que el consentimiento del tratamiento hormonal dependerá de la madurez del menor que se valorará según criterio médico.

\footnotetext{
34 «El Sistema Nacional de Salud incluirá la asistencia sanitaria necesaria para el tratamiento hormonal, terapia de voz, cirugías genitales, mamoplastias, mastectomías y material protésico en la cartera de servicios comunes en las condiciones que se establezcan.

Dicha asistencia sanitaria incluirá el acompañamiento en todos los aspectos de la salud física y mental de la persona».
} 
Al no establecer ninguna edad que estipule cuando se entenderá que el menor tiene suficiente capacidad, se mantendrá la dispersión legislativa autonómica actual ${ }^{35}$.

Con el ánimo de desvincular por completo la transexualidad con cualquier trastorno psiquiátrico el art. 26.3 estipula que la existencia de un diagnóstico de enfermedades psiquiátricas previas no obstará a la validez del consentimiento libremente formulado para la transición de género. Este artículo es totalmente contrario al vigente art. 4.1.a). 2 de la Ley 3/2007 donde se exige un informe que determine la ausencia de trastornos de personalidad que pudieran influir en la existencia del conflicto en el sexo morfológico y el sexo sentido. Igualmente, esta disposición demuestra la incoherencia dentro del propio borrador, ya que para los mayores de 16 años se exige capacidad suficiente, pero a su vez si tienen un diagnóstico de enfermedad psiquiátrica no será obstáculo para obtener el cambio registral del sexo. Entonces ¿qué es la capacidad suficiente requerida en el art. 9? ¿Será el encargado del RC quién deba decidir que a pesar de existir trastornos psiquiátricos esa persona dispone de capacidad suficiente? La inseguridad jurídica está servida.

Posiblemente sería más garantista regular procedimientos concretos donde los profesionales de la Psicología o la Psiquiatría fuesen los encargados de determinar que el trastorno de la personalidad de la persona trans no es el motivo generador de la disconformidad con el sexo morfológico, y posteriormente establecer bajo criterios específicos qué se entiende por capacidad suficiente y quién debe apreciarlo o como debe acreditarse.

Otra disposición que ha causado revuelo mediático es la prohibición, a pesar de que así lo quiera la persona interesada del uso de terapias aversivas y de cualquier otro procedimiento que suponga un intento de conversión, anulación o supresión de la identidad de género, o que estén basados en la suposición de que cualquier identidad de género es consecuencia de enfermedad o trastorno (art. 26.2). Sin embargo, no se trata de una medida innovadora, sino más bien de una medida unificadora de criterios, ya que varias CCAA en sus legislaciones establecían estas terapias dentro de sus prohibiciones, así, por ejemplo, la Ley 2/2016, de 29 de marzo, de Identidad y Expresión de Género e Igualdad Social y no Discriminación de la Comunidad de Madrid $^{36}$. Igualmente, Andalucía, Cantabria, Valencia y Aragón contienen esta prohibición expresa.

\section{Conclusiones}

Este borrador podría tildarse de ambicioso para hacer efectivo el ejercicio del derecho a la autodeterminación de género libre. Se trata de un texto que pretende configurar

\footnotetext{
35 En Aragón un menor mayor de 14 años puede consentir el tratamiento hormonal por sí solo, mientras que en Madrid para otorgar el consentimiento al tratamiento hormonal por sí mismo debe tener más de 16 años y en Valencia en todo caso, el menor no puede consentir por sí mismo, sino a través de sus representantes legales debiendo ser escuchado.

${ }^{36}$ BOE núm. 169, 14 de julio de 2016. Art. 4.3 Ley 2/2016 de 29 de marzo, de Identidad y Expresión de Género e Igualdad Social y no Discriminación de la Comunidad de Madrid «Quedan prohibidas en los servicios sanitarios de la Comunidad de Madrid las terapias de aversión o de conversión de las manifestaciones de identidad de género libremente manifestadas por las personas».
} 
de manera integral la regulación jurídica del colectivo trans más acorde a las recomendaciones emitidas por la Comisión Europea. Sin embargo, hay numerosas sombras en el documento, que podrían provocar cierta inseguridad jurídica y la posible vulneración del interés superior del menor, lo que en último término evita su rápida y pacífica aprobación.

Así, este borrador podría ser el fin de la identificación por sexo y, por ende, el fin de la clasificación por sexos en ámbitos como el deportivo, el escolar en su caso o en el sistema penitenciario. Pero lo verdaderamente preocupante del posible fin de esta clasificación por sexo es el panorama de inseguridad jurídica que se abriría con la aplicación de las leyes que persiguen la igualdad entre hombres y mujeres, siendo esencial la identificación por sexo para ser aplicadas o qué ocurriría con la ley que tipifica la violencia específica de hombres a mujeres dentro de una relación afectiva.

Igualmente, parece pecar este borrador de excesiva innovación en cuanto al establecimiento de la edad para iniciar el trámite del cambio de sexo sin necesidad de argumentar madurez o requerir la intervención de los representantes legales en el proceso. Establecer que los menores de 16 y 17 años puedan libremente cambiar su mención registral relativa al sexo podría llegar a vulnerar el principio del interés superior del menor.

Sin embargo, este documento se trata de un borrador que aún no tiene fecha prevista para su debate, y parece que la vigente Ley 3/2007 seguirá siendo el corpus legal aplicable para el cambio de la mención registral relativa al sexo, ya que no solo no hay previsión aún de debate de este borrador, sino que con la aprobación del Anteproyecto de Ley integral para la igualdad de trato y la no discriminación (conocida como Ley Zerolo) se ha mitigado el impulso para la aprobación de la ley trans.

De esta manera, permanecerá la dispersión legislativa a la que está sometido el colectivo trans, disfrutando de unos derechos u otros y teniendo que cumplir distintos requisitos dependiendo de la CCAA en la que se resida. Paralelamente, España seguirá siendo uno de los países europeos donde el cambio registral del sexo está sometido a criterios médicos contraviniendo la despatologización de la transexualidad que ha establecido la OMS y que persigue como estrategia para la igualdad de este colectivo la Comisión Europea.

\section{Bibliografía}

ÁLVAREZ, F. C. (2009). "Instrucciones de la DGRN". Notarios del siglo XXI(23).

BENÍTEZ, O. S. (2015). "La identidad de género como derecho emergente". Revista de estudios políticos(169), 75-107.

BERCOVITZ RODRÍGUEZ-CANO, R. (2011). Manual de derecho civil. Derecho privado y Derecho de la persona (Quinta ed.). Madrid: Bercal, S.A. 
BERDEJO, J. L., REBULLIDA, F. D., \& AGUSTÍN LUNA SERRANO, J. D. (2008). Elementos de derecho civil I parte general. Personas (Quinta ed., Vol. II). Madrid: Dykinson.

CORRAL, B. A. (2003). Minoría de edad y derechos fundamentales. Madrid: Tecnos. CROVETTO, B. S. (2014). Del derecho a la identidad de género al tratamiento integral de la transexualidad (normativa estatal y autonómica). Estudio doctrinal, Ministerio de Justicia.

FERRER, M.-R. L. (2008). "Una Ley civil para la transexualidad". Indret: Revista para el análisis del derecho(1).

FREYRE, J. M. (2018). "La mayoría de edad como requisito para la rectificación registral del sexo y el nombre: una cuestión de derechos fundamentales". Revista sobre la infancia y la adolescencia(14), 39-52.

GRAU, J. M. (2017). "Del transexualismo a la disforia de género en el DSM. Cambios terminológicos, misma esencia patologizante". Revista Internacional de Sociología.

HOYO, M. V. (2016). "El sexo de la persona: ¿Un estado civil en el derecho español?" Revista de ciencias jurídicas(139), 31-56.

LOSANA, A. I. (3 de Noviembre de 2018). ¿Cuando puede una persona cambiar su nombre en el Registro Civil para adecuarlo al sexo sentido? Toledo, España.

MARSAL, C. (junio de 2011). "Los principios de Yogyakarta: derechos humanos al servicio de la ideología de género". Dikaion, 20(1), 119-130.

MONZONÍS, C. A., \& MARCO, R. M. (2012). "Nombres propios, identidad y dignidad". Revista de investagación lingüistica(15), 161-185.

MORENO, Y. B. (2008). La transexualidad (De acuerdo a la Ley 3/2007, de 15 de marzo). Madrid: Dykinson, S.L.

Organización Mundial de la salud (18 de JUNIO de 2018). Organización Mundial de la Salud. Obtenido de: https://www.who.int/es/news-room/detail/17-06-2018-whoreleases-new-international-classification-of-diseases-(icd-11)

PÉREZ-PEDRERO, E. B. (2004). "Transexualidad y DF: protección integral sin la utilización del factor sexo como diferencia". Cuadernos de derecho público(21), 127161.

QUESADA, B. M., PORRAS, J. M., SERRANO, J. M., RICO-MORÓN, J. R.-R., GARCÍA, J. G., CAMPOS, R. H., \& QUESADA, L. M. (2017). Curso de derecho civil I. Parte general y derecho de la persona. (séptima ed.). Valencia: Tirant To Blanch.

RÍO, J. A. (2015). "La regulación de la identidad de género en las comunidades autónomas" . Actualidad jurídica Iberoamericana, 745-760. 
RÍO, J. A. (2016). "Menores transexuales. Su protección jurídica en la constitución y en la legislación española". Revista Española de Derecho Constitucional(107), 153186.

RODRÍGUEZ, M. F., \& GARCÍA-VEGA, E. (2012). "Surgimiento, evolución y dificultades de diagnóstico de transexualismo". Revista de la Asociación Española de Neuropsiquiatría(32), 103-119.

RODRÍGUEZ-CANO, R. B. (2018). "Personas transexuales y estado de derecho". Revista Doctrinal Aranzadi Civil-Mercantil(11), 4.

SANCHO, V. M. (enero de 2018). "Una revisión de la jurisprudencia del Tribunal Europeo de Derechos Humanos sobre la intimidad sexual y la autonomía individual". Derechos y Libertades, II(38), 327-358. 